\title{
Integrating timescales with time-transfer functions: a practical approach for an INTIMATE database
}

\author{
Christopher Bronk Ramsey ${ }^{*}{ }^{1}$ Paul Albert ${ }^{1}$ Simon Blockley ${ }^{2}$ \\ Mark Hardiman ${ }^{2}$ Christine Lane ${ }^{1}$ Alison Macleod ${ }^{2}$ \\ Ian P. Matthews ${ }^{2}$ Raimund Muscheler ${ }^{3}$ Adrian Palmer ${ }^{2}$ \\ Richard A. Staff ${ }^{1}$ \\ * christopher.ramsey@rlaha.ox.ac.uk +44 1865285215
}

\begin{abstract}
The purpose of the INTIMATE project is to integrate palaeo-climate information from terrestrial, ice and marine records so that the timing of environmental response to climate forcing can be compared in both space and time. One of the key difficulties in doing this is the range of different methods of dating that can be used across different disciplines. For this reason, one of the main outputs of INTIMATE has been to use an event-stratigraphic approach which enables researchers to co-register synchronous events (such as the deposition of tephra from major volcanic eruptions) in different archives (Blockley et al., 2012). However, this only partly solves the problem, because it gives information only at particular short intervals where such information is present. Between these points the ability to compare different records is necessarily less precise chronologically. What is needed therefore is a way to quantify the uncertainties in the correlations between different records, even if they are dated by different methods, and make maximum use of the information available that links different records.

This paper outlines the design of a database that is intended to provide integration of timescales and associated environmental proxy information. The database allows for the fact that all timescales have their own limitations, which should be quantified in terms of the uncertainties quoted. It also makes use of the fact that each timescale has strengths in terms of describing the data directly associated with it. For this reason the approach taken allows users to look at data on any timescale that can in some way be related to the data of interest, rather than specifying a specific timescale or timescales which should always be used. The information going into the database is primarily: proxy information (principally from sediments and ice cores) against depth, age-depth models against reference chronologies (typically IntCal or ice core), and time-transfer functions that relate different timescales to each other, through the use of event stratigraphies or global phenomena such as cosmogenic isotope production rate variations.
\end{abstract}


Key words: Dating, Statistics, Radiocarbon, Calibration, Sediment, Lateglacial, Quaternary environments, Ice cores, Tephra

\section{Introduction}

The purpose of the INTIMATE initiative is to make independent comparisons of the timing and duration of abrupt climatic changes over the last 60 ka by facilitating the comparison and integration of marine, terrestrial and ice core records (Blockley et al., 2012). Lowe et al. (2008) suggest that within the INTIMATE approach individual studies should generate proxy data with their own robust chronologies for well-resolved sites and then define the local and/or regional climatic events. Once this has been achieved comparisons can then be drawn between other sites and, for example, the Greenland event stratigraphy. However, this may only be attempted when the full range of stratigraphic and chronological uncertainties present in all comparable sequences are considered. Without this structured approach chronological uncertainties within and between records hinder the testing of competing theories surrounding the mechanisms of abrupt climate change (Lowe et al. 2008). For this reason it is necessary to quantify the uncertainties in the correlations between different records and make maximum use of the information that is available to link records. A process for achieving this is outlined below and has been integrated into visualisation software for the wider community, thereby facilitating the INTIMATE approach to palaeoclimatic research.

Central to any questions of timing and duration is the definition of timescales. Some timescales are useful as main reference timescales which can be used to allow direct comparison of ages from different records; in this category are the IntCal calibrated radiocarbon timescales (Reimer et al., 2009, 2013), and the Greenland GICC05 timescale (Andersen et al., 2006; Rasmussen et al., 2006, 2008; Svensson et al., 2006, 2008). Importantly, information on the relationship between these primary timescales is also available, based on the comparison of globally synchronous variations in the radionuclide production rates (Muscheler et al., submitted). However, if data are only referenced against these common timescales, with proper accounting for the full chronological uncertainties, it becomes difficult to study duration and relative timing of climatic and other events. Therefore, it is important also to maintain site-specific

1 Research Laboratory for Archaeology and the History of Art, University of Oxford, Dyson Perrins Building, South Parks Road, Oxford, OX1 3QY

2 Department of Geography, Royal Holloway University of London, Egham, Surrey, TW20 0EX, UK

3 Geologiska Institutionen, Lunds Universitet, Sölvegatan 12, 22362 Lund, Sweden 
timescales because, fundamentally, proxy data are provided against depth and the local timescale provides a convenient way to look at data at high-resolution with units that do not depend on deposition rate. The approach taken here is to allow all data to be observed relative to any time or depth scale with all of the associated uncertainties. The aim is to provide a tool (available online at https://c14.arch.ox.ac.uk/intimate/db.php) to quickly explore data from different perspectives so that researchers can better understand what the available data reveal about past climate change.

The work presented here arises out of two scientific meetings supported by the EU-funded COST (European Cooperation in Science and Technology) INTIMATE initiative. The first of these was a workshop held at Oxford in December 2012 which looked at different ways of presenting data and considered how best to use the relationships between different timescales. This was followed by the INTIMATE meeting at Blair Atholl in April 2013 where the INTIMATE group as a whole helped to pull together the information which is held in the database described here. These meetings provided an opportunity to pool information in ways that had not been possible before, and to start the process of compiling datasets. However, what is presented here is inevitably just the first stage in what must be a continuous process. This paper specifically presents the mathematical basis for the integration of records and explains how users might navigate through the database tool in order to add and compare Late Quaternary records.

\section{Mathematical methodology}

In setting out the mathematical formalism for the approach taken here, it is necessary to make a number of approximations and simplifications. This is in part because of the complexity and range of the different datasets being integrated, but it is also because it is useful to have a formalism for integration that can be carried out rapidly as new data are included and does not require a major remodelling effort as each new dataset is added.

The problem of complexity in the data is perhaps the most obvious. Much of the information available is based on non-normal statistics (so, for example, maximum counting errors in ice core ages, and proxy information expressed in terms of depth ranges, rather than with a depth uncertainty). It would be possible, in principle, to include all of this information into a mathematical model and use a method such as Monte Carlo Markov Chain (MCMC) with Bayesian formalism to combine all uncertainties. However, while this might well be practical on a small scale, the other main problem is that, in principle, every dataset is related in some way to every other dataset, and so as new information is added everything should be reviewed and reassessed. Thus, the 
model required would have to encompass the full dataset and this is, at present anyway, impractical.

For these reasons the method presented here breaks the integration process up into a number of manageable stages and makes some simplifying assumptions. This is a pragmatic approach which allows flexibility in the kind of information included, but it does mean that there will be approximations made in the process that users should be aware of from the start. The approach is one of propagation of normal errors.

The methodology is perhaps most easily understood in terms of an example. Supposing we wish to date a series of proxy samples in site A (for example Kråkenes). The first stage might be to use an age-depth model, based on radiocarbon, to provide a central estimates of age $\left(t_{A}\right)$ for the depths in that site; this provides an internal site-specific timescale, useful for internal comparison purposes. However, the central age estimates are ultimately derived from the IntCal calibration curve (B) and, although the central estimate for the date in this timescale $\left(t_{B}\right.$, the IntCal timescale) is the same, there is uncertainty associated with it, which comes from the calibration and age-depth modelling exercises; this uncertainty needs to be taken into consideration if comparisons to other radiocarbon dated material is to be made. Furthermore, you might wish to compare the data from Kråkenes to that from another record C (for example the NGRIP record). This would require an estimate in the timescale for that record $\left(t_{C}\right.$, which in this case is GICC05), requiring information on the relationship between $t_{B}$ and $t_{C}$.

\subsection{Proxy information}

The reason for the study of most environmental sites is the associated proxy data. In general such data are collected from material in a core or section and thus there is a direct relationship between the proxy data and the section's associated depth scale. Another complication is that many such cores or sections have different depth scales (for example: individual core depth, composite depth, or event-free depth). It makes sense for those with expertise in the record itself to define the most appropriate depth scale to use. However, it is also important to bear in mind what this depth will be used for. In the methodology outlined here it will be assumed that between datapoints in an age-depth model it is possible to linearly interpolate age from depth. This means that a single monotonic depth scale should be used and, if possible, this should be an event-free depth (excluding layers attributed to macroscopic, instantaneous deposits, e.g. from floods, turbidites, visible tephra etc., see Schlolaut et al. (2012) and see Fig. 1) as this will give more accurate interpolation. 

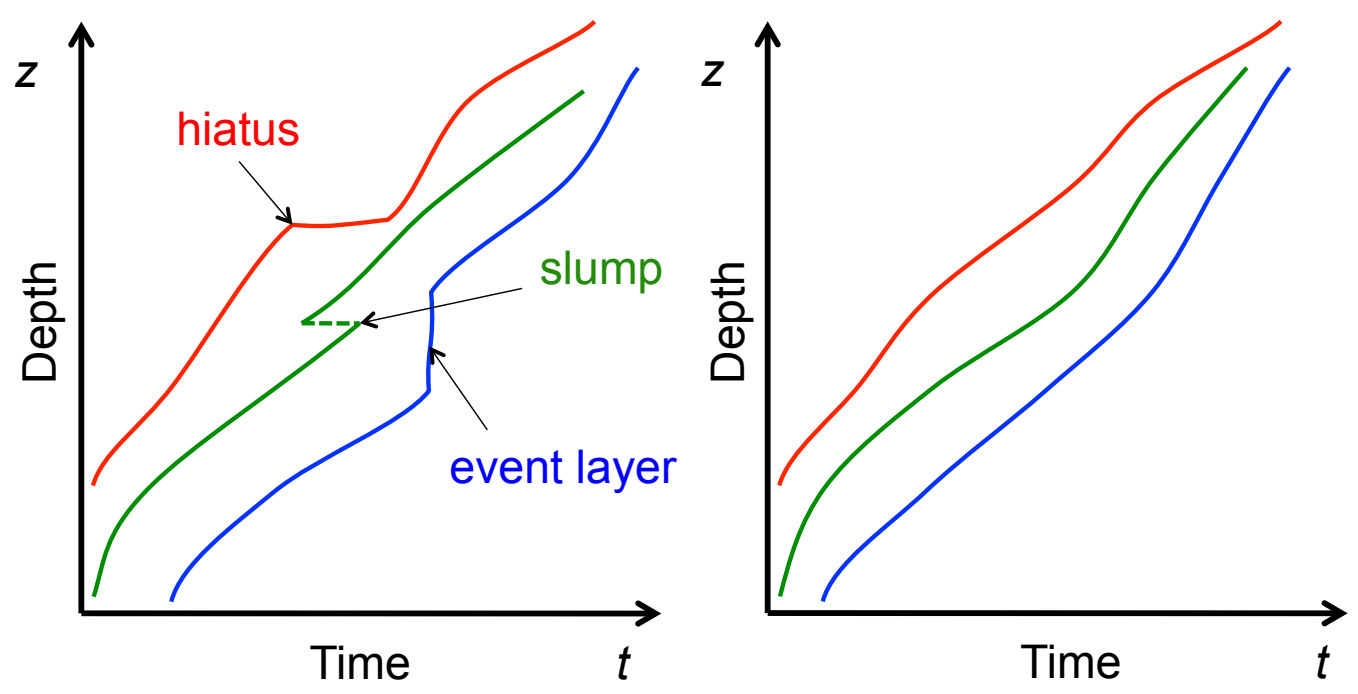

Fig. 1. The left hand plot shows common problems with age-depth relationships in real sediments; it is important that these types of problem are identified and dealt with either by using separate segments for records, or by using event-free depth scales; the right hand plot shows what is required for this exercise in that age must be a strictly monotonic increasing function of depth and vice-versa.

Our primary proxy data for a particular data series are given at specific points in the record. Let the record be labelled $A$, the index corresponding to the specific depth $i$ and the actual (average) depth be $z_{A}^{i}$; the central estimate for this depth is given as $h_{A}^{i}$ with an unknown error from the true value of $\zeta_{A}^{i}$. Typically sampling is perfumed over a depth range (defined as $r_{A}^{i}$ ) and so strictly follows a uniform distribution $\zeta_{A}^{i} \sim U\left(-r_{A}^{i} / 2, r_{A}^{i} / 2\right)$. Because the methodology used here relies on normal errors, this is approximated to a normal distribution $(\mathcal{N})$ with the same variance.

$$
\begin{aligned}
z_{A}^{i} & =h_{A}^{i}+\zeta_{A}^{i} \\
\zeta_{A}^{i} & \sim \mathcal{N}\left(0,\left(r_{A}^{i}\right)^{2} / 12\right) \\
& \sim \mathcal{N}\left(0,\left(s_{A}^{i}\right)^{2}\right) \\
\text { where } s_{A}^{i} & =\frac{r_{A}^{i}}{2 \sqrt{3}}
\end{aligned}
$$

The errors $\zeta_{A}^{i}$ in $z_{A}^{i}$ are likely to be uncorrelated.

For each depth (index $i$ ) there might be a whole array of different proxy measures, each of which could have an uncertainty associated with it (quoted within this database as a $1 \sigma$ standard uncertainty). For display purposes straight lines are drawn between successive datapoints and so it is impor- 
tant to remember to mark within the data series where there are gaps in data (see section 3).

\subsection{Age-depth models}

In order for data series to be useful in this context, there must be an age-depth model. These can be produced by different methods (see, for example, Blaauw and Christen, 2005; Bronk Ramsey, 2008; Scholz and Hoffmann, 2011; Heaton et al. 2013). The purpose of an age-depth model is to provide a functional relationship for the age of a record against depth, based on the primary dating information. Such a model will do more than simply interpolate between the dated events, and any significant non-linearities in the age-depth profile should be dealt with at the modelling stage. It is also essential that any such agedepth model should have an uncertainty associated with it. Here, in order to keep the algorithms simple, another assumption is made, and that is that the age-depth model uncertainties can be adequately summarised by a mean and standard uncertainty. In practice, many of the Bayesian methods employed yield non-normal marginal posterior distributions but fortunately, for many models where there is a high density of scientific dating information yielding high-precision age-depth models, the age distributions for particular depths are well approximated by normal distributions. Other methods such as Gaussian process (GP) models (Heaton et al., 2013) give results in this form anyway. In practice the uncertainties in any age-depth model are highly covariant (Heaton et al., 2013; Bronk Ramsey and Lee, 2013), a point which will be discussed below.

At this point it is necessary to introduce an important aspect of the integration exercise, which is that the defined age-depth model is assumed to be related to some reference time-scale $\left(t_{B}\right)$, or using a particular direct dating method. For example the age-model might be based on a specific IntCal calibration curve, an ice core chronology, or use a direct dating method such as UraniumThorium dating. The relationship between these different methods of dating is something that will be discussed further below (sub-section 2.3).

An age-depth model is, in principle, capable of yielding output at any required resolution. In practice, the output from these models is only given at specific depths (sometimes, but not always, the same as the best estimate depths, $h_{A}^{i}$, of the record). It is important that the output is sufficiently closely spaced that it is possible to linearly interpolate between the output points to recover a full functional relationship between depth and time (implying that any nonlinearities are small compared to the quoted precision of the age-depth model). It is also assumed that the age-depth function is strictly monotonic, so that an inverse can be defined, and differentiable. For any depth $z_{A}$ the age-depth 
model will be defined to be $t_{A}=f_{A}\left(z_{A}\right)$. This will be relative to the reference timescale $t_{B}$ against which there will be an unknown time-dependent error $\epsilon_{A B}\left(t_{A}\right)$ (or depth-dependent as $\epsilon_{A B}\left(f\left(z_{A}\right)\right)$ ). Thus:

$$
\begin{aligned}
& t_{A}=f_{A}\left(z_{A}\right) \\
& t_{B}=t_{A}+\epsilon_{A B}\left(t_{A}\right)
\end{aligned}
$$

It is useful to keep the concept of a local timescale $t_{A}$ which is essentially a proxy for depth, but with the units of time, and which takes into account the changes in deposition rate elucidated through the age-depth model. Even in this timescale there is uncertainty in the age of proxy data if there is depth uncertainty. Using a Taylor-series, to first order:

$$
\begin{aligned}
t_{A}^{i} & =f_{A}\left(h_{A}^{i}+\zeta_{A}^{i}\right) \\
& \approx f_{A}\left(h_{A}^{i}\right)+f_{A}^{\prime}\left(h_{A}^{i}\right) \zeta_{A}^{i} \\
t_{A}^{i} & \sim \mathcal{N}\left(f_{A}\left(h_{A}^{i}\right),\left(f_{A}^{\prime}\left(h_{A}^{i}\right) s_{A}^{i}\right)^{2}\right)
\end{aligned}
$$

The central estimate for the age in the reference timescale is the same, but error is introduced. In order to anticipate the next stage of this process this can be defined as a time transfer function $G_{A B}\left(t_{A}\right)$ with a central estimate of $g_{A B}\left(t_{A}\right)=t_{A}$ :

$$
\begin{aligned}
t_{B} & =G_{A B}\left(t_{A}\right) \\
& =g_{A B}\left(t_{A}\right)+\epsilon_{A B}\left(t_{A}\right)
\end{aligned}
$$

In addition to providing the central estimate of age against depth, $f_{A}\left(z_{A}\right)$, the age-depth modelling process will quantify the likely error $\epsilon_{A B}\left(t_{A}\right)$. For a single point estimate of age it is assumed that the error is quantified by a time-dependent variance $\sigma_{A B}^{2}\left(t_{A}\right)$ (which could also be considered to be depthdependent as $\sigma_{A B}^{2}\left(f_{A}\left(z_{A}\right)\right)$.

$$
\epsilon_{A B}\left(t_{A}\right) \sim \mathcal{N}\left(0, \sigma_{A B}^{2}\left(t_{A}\right)\right)
$$

However, it should be noted that unlike the depth uncertainty, this error function is likely to be highly covariant: that is there will be a strong correlation between $\epsilon_{A B}\left(t_{A}^{i}\right)$ and $\epsilon_{A B}\left(t_{A}^{j}\right)$ where $t_{A}^{i}$ and $t_{A}^{j}$ are close in value. This need not matter when calculating single values but it must be kept in mind with a whole series of calculations. One reason that this function must be highly covariant is that the function $G_{A B}\left(t_{A}\right)$ must be monotonic. Given that the gradient of the central tendency is in this case exactly 1 , the magnitude of the 
gradient in the error function $\epsilon_{A B}\left(t_{A}\right)$ is expected to be $\ll 1$. Later it will be assumed that the age-depth gradient defined by the age-depth model will be approximately correct - a point which actually relies on the highly covariant nature of the errors.

\section{Example age-depth model application}

The methodology so far will be illustrated with a specific example. The loss on ignition (LOI) data from Kråkenes (Lohne et al., 2013) core 46 are given for specific depths $\left(z_{A}^{i}\right)$. The age-depth model gives an estimate of the age (and the associated uncertainty) against IntCal09 and outputs a value at $1 \mathrm{~cm}$ intervals, between which it is possible to interpolate linearly, giving a continuous function $f_{A}\left(z_{A}\right)$ (being the central estimate of the age-depth model). For any depth $z_{A}$ in the Kråkenes core this function can be used to find the age in the local timescale $\left(t_{A}\right)$. This timescale can be used to plot the LOI data, as an alternative to plotting it directly against depth. By analogy this is similar to the practice of plotting NGRIP $\delta^{18} \mathrm{O}$ data against the GICCO5 timescale. To compare to any other site, it would also be possible to plot the Kråkenes data against the IntCal09 timescale $\left(t_{B}\right)$. To do this it is necessary to take account of the uncertainty in the age-depth model defined by the variance in the age-depth model $\sigma_{A B}^{2}\left(t_{A}\right)$.

\section{Using age-depth models for proxy data}

In general for any particular proxy at level $z_{A}^{i}$, in a record which is calibrated to the IntCal calibration curve (timescale $t_{B}$ ), to first order in $z_{A}$ :

$$
\begin{aligned}
t_{B}^{i} & =t_{A}^{i}+\epsilon_{A B}\left(t_{A}^{i}\right) \\
& =f_{A}\left(z_{A}^{i}\right)+\epsilon_{A B}\left(f_{A}\left(z_{A}^{i}\right)\right) \\
& =f_{A}\left(h_{A}^{i}+\zeta_{A}^{i}\right)+\epsilon_{A B}\left(f_{A}\left(h_{A}^{i}+\zeta_{A}^{i}\right)\right) \\
& \approx f_{A}\left(h_{A}^{i}\right)+f_{A}^{\prime}\left(h_{A}^{i}\right) \zeta_{A}^{i}+\epsilon_{A B}\left(f_{A}\left(h_{A}^{i}\right)\right)+\epsilon_{A B}^{\prime}\left(f_{A}\left(h_{A}^{i}\right)\right) f_{A}^{\prime}\left(h_{A}^{i}\right) \zeta_{A}^{i}
\end{aligned}
$$

Given, the covariant nature of $\epsilon_{A B}\left(t_{A}\right)$ discussed above, the final term should be small in comparison to the second and thus:

$$
\begin{aligned}
& t_{B}^{i} \approx f_{A}\left(h_{A}^{i}\right)+f_{A}^{\prime}\left(h_{A}^{i}\right) \zeta_{A}^{i}+\epsilon_{A B}\left(f_{A}\left(h_{A}^{i}\right)\right) \\
& t_{B}^{i} \sim \mathcal{N}\left(f_{A}\left(h_{A}^{i}\right),\left(f_{A}^{\prime}\left(h_{A}^{i}\right) s_{A}^{i}\right)^{2}+\sigma_{A B}^{2}\left(f_{A}\left(h_{A}^{i}\right)\right)\right.
\end{aligned}
$$

where the first element in the variance comes from the uncertainty in the depth and the second from the uncertainty in the age-depth model. 


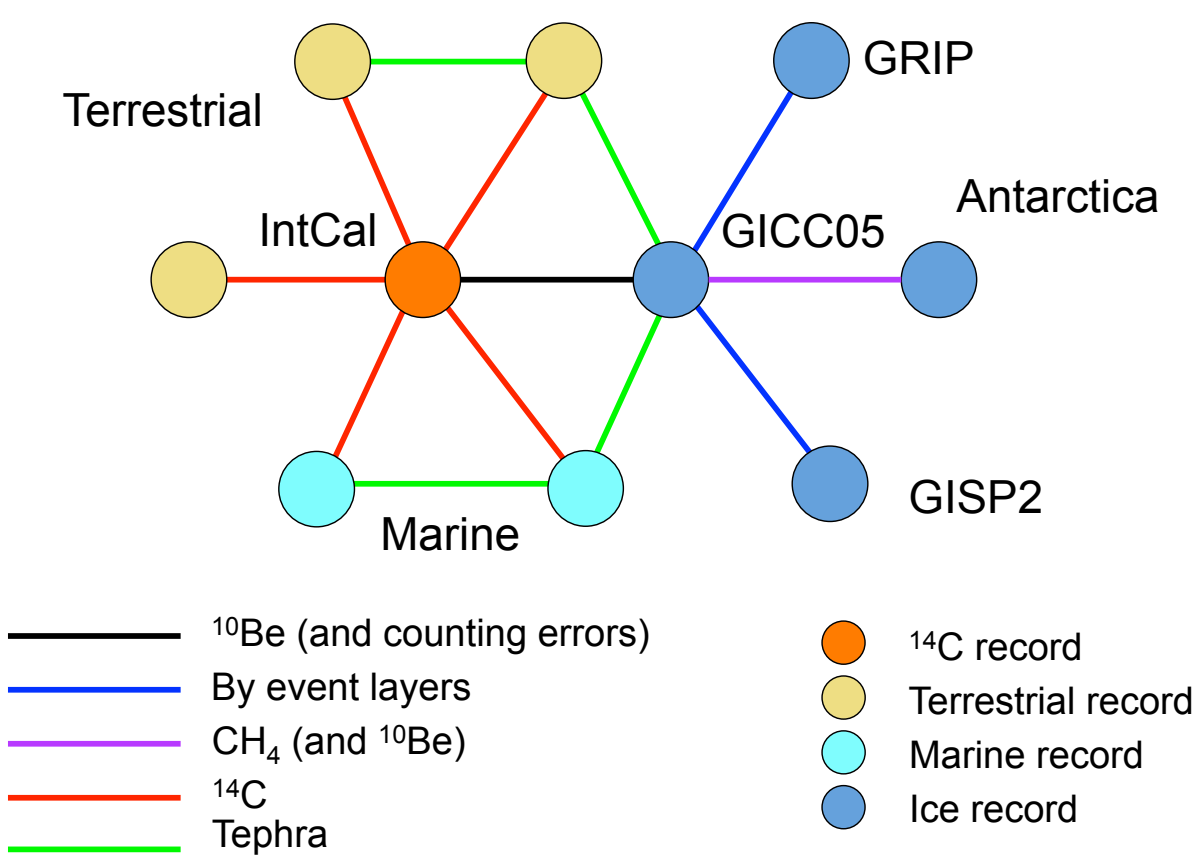

Fig. 2. Schematic showing how the database can be used to integrate records. Each node can represent either a specific environmental record (such as that for the site of Kråkenes, or GRIP), or a composite record/timescale (such as GICC05 and IntCal). In the case of a composite record/timescale, this can contain proxy data compilations, or simply be a timescale used for a number of different site-specific records, thereby providing an important node for record integration.

\subsection{Time-transfer functions}

There are other ways in which different timescales can be directly related to one another (see Fig. 2). Time scale transfer functions are usually based on the identification of common events in different records. Transfer functions are preferentially inferred from climate-independent and physically understood linkages between proxies in different natural archives. For example, these include gas measurements in ice cores (as long-lived atmospheric gases are relatively well mixed globally) or linkages via identification of tephra layers that can be geochemically identified and unequivocally connected to one source. It is also possible to relate the IntCal timescale $\left(t_{B}\right)$ to that of the Greenland ice cores $\left(t_{C}\right)$ through comparison of ${ }^{10} \mathrm{Be}$ and ${ }^{14} \mathrm{C}$ variations (Muscheler et al., submitted), or the Greenland and Antarctic timescales through methane and ${ }^{10}$ Be synchronisation (Lemieux-Dudon et al., 2010). Less obviously, there is information on the relationship between timescales whenever there are terrestrial, marine or ice sites that share the same tephra. 
Mathematically, such relationships between two different timescales $\left(t_{B}\right.$ and $t_{C}$ ) can be defined by providing point estimates of one timescale $\left(t_{C}\right)$ relative to another $\left(t_{B}\right)$, and by quantifying the uncertainty in these relationships. As for the age-depth models above, it is important that the method used to generate this relationship outputs relative values at high enough density that it is legitimate to linearly interpolate between points to give a continuous function $G_{B C}\left(t_{B}\right)$ with a central estimate of $g_{B C}\left(t_{B}\right)$ :

$$
\begin{aligned}
t_{C} & =G_{B C}\left(t_{B}\right) \\
& =g_{B C}\left(t_{B}\right)+\epsilon_{B C}\left(t_{B}\right) \\
\epsilon_{B C}\left(t_{B}\right) & \sim \mathcal{N}\left(0, \sigma_{B C}^{2}\left(t_{B}\right)\right)
\end{aligned}
$$

where $\sigma_{B C}^{2}\left(t_{B}\right)$ is the variance. Again as above the function $\epsilon_{B C}\left(t_{B}\right)$ is expected to be strongly covariant for similar values of $t_{B}$. When such a time transfer function is applied to a record which has been age-depth modelled, this gives:

$$
\begin{aligned}
t_{C} & =G_{B C}\left(t_{A}+\epsilon_{A B}\left(t_{A}\right)\right) \\
& =g_{B C}\left(t_{A}+\epsilon_{A B}\left(t_{A}\right)\right)+\epsilon_{B C}\left(t_{A}+\epsilon_{A B}\left(t_{A}\right)\right) \\
& \approx g_{B C}\left(t_{A}\right)+g_{B C}^{\prime}\left(t_{A}\right) \epsilon_{A B}\left(t_{A}\right)+\epsilon_{B C}\left(t_{A}\right)+\epsilon_{B C}^{\prime}\left(t_{A}\right) \epsilon_{A B}\left(t_{A}\right)
\end{aligned}
$$

The gradient of the function $g_{B C}\left(t_{B}\right)$ will be approximately 1 . For the same reasons as discussed above, the function $\epsilon_{B C}^{\prime}\left(t_{B}\right)$ should have a magnitude $\ll 1$; or to put it another way, it is assumed that $G_{B C}^{\prime}\left(t_{B}\right) \approx g_{B C}^{\prime}\left(t_{B}\right)$. This means that the final term in this equation is small in comparison to the second, giving:

$$
\begin{aligned}
t_{C} & \approx g_{B C}\left(t_{A}\right)+g_{B C}^{\prime}\left(t_{A}\right) \epsilon_{A B}\left(t_{A}\right)+\epsilon_{B C}\left(t_{A}\right) \\
t_{C} & \sim \mathcal{N}\left(g_{B C}\left(t_{A}\right),\left(g_{B C}^{\prime}\left(t_{A}\right) \sigma_{A B}\left(t_{A}\right)\right)^{2}+\sigma_{B C}^{2}\left(t_{A}\right)\right)
\end{aligned}
$$

To return to the specific example, this would allow the timescale of a particular site like Kråkenes $\left(t_{A}\right)$ to be expressed in terms of the GICC05 timescale $\left(t_{C}\right)$ given a functional relationship $\left(G_{B C}\right)$ between the IntCal09 timescale $\left(t_{B}\right)$ and the GICCO5 timescale $\left(t_{C}\right)$. Indeed, for any point with an estimated depth $h_{A}^{i}$ with uncertainty $s_{A}^{i}$ in such a record, it is possible to define the age in terms of three different timescales: 


$$
\begin{aligned}
t_{A}^{i} \sim & \mathcal{N}\left(f_{A}\left(h_{A}^{i}\right),\left(f_{A}^{\prime}\left(h_{A}^{i}\right) s_{A}^{i}\right)^{2}\right) \\
t_{B}^{i} \sim & \mathcal{N}\left(f_{A}\left(h_{A}^{i}\right),\left(f_{A}^{\prime}\left(h_{A}^{i}\right) s_{A}^{i}\right)^{2}+\sigma_{A B}^{2}\left(f_{A}\left(h_{A}^{i}\right)\right)\right. \\
t_{C}^{i} \sim & \mathcal{N}\left(f_{A}\left(h_{A}^{i}\right),\right. \\
& \left(g_{B C}^{\prime}\left(f_{A}\left(h_{A}^{i}\right)\right) f_{A}^{\prime}\left(h_{A}^{i}\right) s_{A}^{i}\right)^{2} \\
& +\left(g_{B C}^{\prime}\left(f_{A}\left(h_{A}^{i}\right)\right) \sigma_{A B}\left(f_{A}\left(h_{A}^{i}\right)\right)\right)^{2} \\
& \left.+\sigma_{B C}^{2}\left(f_{A}\left(h_{A}^{i}\right)\right)\right)
\end{aligned}
$$

where the first element in the variance comes from the uncertainty in the depth, the second from the age-depth model and the third from the transfer from timescale $t_{B}$ to $t_{C}$. Conceptually, each change of timescale adds extra variance to the age estimate.

Inverse functions can also be easily generated allowing, for example, data on the GICC05 timescale to have age estimates in the IntCal timescale, in the local timescale of a specific record like that of Kråkenes, or indeed on the depth-scale of that core. The inverse time-transfer functions can be defined to first order as:

$$
\begin{aligned}
t_{B} & =G_{C B}\left(t_{C}\right) \\
& =g_{B C}^{-1}\left(t_{C}-\epsilon_{B C}\left(t_{B}\right)\right) \\
& \approx g_{B C}^{-1}\left(t_{C}\right)-\frac{1}{g_{B C}^{\prime}\left(g_{B C}^{-1}\left(t_{C}\right)\right)} \epsilon_{B C}\left(g_{B C}^{-1}\left(t_{C}\right)\right) \\
g_{C B}\left(t_{C}\right) & \approx g_{B C}^{-1}\left(t_{C}\right) \\
\sigma_{C B}^{2}\left(t_{C}\right) & \approx\left(\frac{1}{g_{B C}^{\prime}\left(g_{B C}^{-1}\left(t_{C}\right)\right)} \sigma_{B C}\left(g_{B C}^{-1}\left(t_{C}\right)\right)\right)^{2}
\end{aligned}
$$

Likewise, if the total variance in $t_{A}$ is given by $\sigma_{A}^{2}$, then the central estimate for the depth $h_{A}$ and its variance $s_{A}^{2}$ are given by:

$$
\begin{aligned}
& h_{A} \approx f_{A}^{-1}\left(t_{A}\right) \\
& s_{A}^{2} \approx\left(\frac{1}{f_{A}^{\prime}\left(t_{A}\right)} \sigma_{A}\right)^{2}
\end{aligned}
$$

In general the uncertainties associated with depth, with age-depth modelling, and with time-transfer functions (such as that between IntCal and GICC05) would be expected to be independent, which is an important assumption underlying the methodology laid out here. This would clearly not be the case if a conversion used the same time-transfer function (or its inverse) more than once. In terms of the network shown in Fig. 2, it is then important that only simple paths are used (i.e. no point is passed through more than once). 
One area where there may be some correlation that is not accounted for is where two different records are independently calibrated to the IntCal timescale using radiocarbon. Some uncertainties in such age-models come from the calibration curve itself and thus are common to both. This is the same problem that arises when comparing two calibrated radiocarbon dates more generally. In practice, the data-density and precision of the calibration curve mean that most of the uncertainty is record specific and this is not a major issue, but this is none-the-less a limitation of current calibration approaches.

\subsection{Integration}

As seen in the previous section time-transfer functions can be used to transform through a series of timescales $(A \rightarrow B \rightarrow C)$. This can be thought of as a network of connected records: the records being the nodes and the timetransfer functions being the paths between nodes (see Fig. 2). In principle with a fully connected network of records this enables any timescale to be related to any other. However, there are some fundamental complications arising from the network topology:

- In general there are many different paths in a network from one point to another. Even if there were only ever one time-transfer function directly connecting two nodes, there would generally still be multiple connections involving one intermediate node or more (for example $A \rightarrow B \rightarrow C \rightarrow D$ and $A \rightarrow B \rightarrow E \rightarrow D$ ).

- Because there is uncertainty associated with the transfer functions, and approximations involved with them, each path taken will almost certainly give a different solution.

- Some paths through the network might pass through the same nodes more than once, and likewise the connections in the network (the time-transfer functions) might be used in different paths.

All of the information imbedded within the network could be incorporated into a global model for relating all of the timescales. However, this would be a very significant computational task, as discussed above. At first it might appear possible to simply transverse all possible paths and combine the results analytically. However, the fact that this would involve different paths sharing some of the same information means that all such estimates cannot be treated as independent. For this reason, in this application an even simpler approach is taken which is to take the value which gives the lowest uncertainty. This will usually be the shortest route through the network since each time-transfer function used introduces extra uncertainty. This will, if anything, tend to overestimate the uncertainty. 
The algorithm employed is:

(1) Where relevant, each record is given its own depth scale $\left(z_{A}, z_{B}, z_{C} \ldots\right)$ against which proxy data are defined.

(2) Each record is assigned its own site-specific timescale $\left(t_{A}, t_{B}, t_{C} \ldots\right)$ which is defined to be exact. Thus, for example, $A$ might be a terrestrial site, $B$ might be the IntCal radiocarbon record, and $C$ the Greenland ice record. The age-model for the terrestrial site provides the specific timescales for that site and IntCal and Greenland have their own reference timescales.

(3) A number of different time-transfer functions, are defined either as part of age-depth models, or derived from other specific synchronisation information. For example, the age-depth models for a terrestrial site, with its associated uncertainty, give time transfer functions relating $t_{A}$ to $t_{B}$ $\left(G_{A B}\left(t_{A}\right)\right)$ and ${ }^{10} \mathrm{Be}$ could be used to relate the IntCal $\left(t_{B}\right)$ and Greenland $\left(t_{C}\right)$ timescales (Muscheler et al., submitted) through a time-transfer function $\left(G_{C B}\left(t_{C}\right)\right)$.

(4) The age-depth models and time-transfer functions are used to provide the age and uncertainty of each point in every record in relation to every timescale within the network, taking into account any depth uncertainty in the proxies. All possible paths through the network are explored and the path which gives the lowest uncertainty at any particular period is selected. Thus, for example, a terrestrial record dated by radiocarbon will have dates in the local timescale with an uncertainty only dependent on depth uncertainty of the proxies; it will have dates in the IntCal timescale which will be the same but will now incorporate the errors associated with the radiocarbon calibration and age-depth modelling; it will have dates on the Greenland timescale which will be slightly different and will have greater uncertainties because there is uncertainty in the relationship between IntCal and Greenland.

(5) Finally, the depth scales (where relevant) from all records are calculated for all proxy data in all records. Thus, for example a particular point in the Greenland record where there might be a climatic excursion can be related to the depth in a specific terrestrial record (but with associated uncertainty from the extended chain of inference). This allows users to see if events are, within errors synchronous in different records, without making any such assumptions.

There are a number of shortcomings in this approach which should be kept in mind when using the results from the integration:

- The age-models are assumed to be correct within their stated uncertainties.

- There are approximations of linear interpolation involved.

- For propagation of errors, a first order approximation is used which assumes a well-behaved relationship between timescales and depth. 
- Some information is discarded because only the highest precision linkage in the network is used; this is conservative and, unless the uncertainties by different routes are similar, is unlikely to be very significant.

- In principle, there is a danger that the monotonic nature of the timescales might not be preserved. If there are linkages between timescales that are only significant in particular periods (for example near tephra), then the timescales could have discontinuities in these regions. In practice this does not seem to be a major problem and is only likely to be so if there are data which are seriously discrepant.

However, despite the simplifications made, the approach set out here provides a powerful way to pull together the available information in a comprehensive way. It has the advantage that mathematically it is simple enough that all the calculations can be made dynamically as a range of different datasets is considered.

\section{Database structure}

In order to allow for practical integration of chronologies, it was considered essential to have a database in which the relevant information could be collected. This means that new data can easily be added, existing data stored and shared between users.

The database structure closely follows the requirements laid out for integration above and is summarised in Figs. 3 and 4. There are eleven main tables in the database:

- sites: this table holds geographical information such as site location and type for the database; each site can, in principle, have more than one record which allows for multiple cores, different speleothems within the same cave etc.; each site can have multiple references which describe the site generally (not specific records).

- records; this holds information on the records themselves and provides the anchor for all of the data associated with that record; each record has linked to it lists of dates associated with it and one (and only one) age-depth model which is used to relate the record to others; there can be any number of series of proxy data associated with the record; there can also be multiple references, at least one of which should provide the background to the agedepth model chosen.

- dates: this is primary dating information associated with a record and provides a simple list of dates of different types against depth; these data are not directly used in the integration of timescales, but is a useful resource should people wish to update age-depth models with new information (such 
as updated radiocarbon calibration curves).

- age-depth: this provides the information for linking age with depth for a particular record; this is the data which provides the age-depth model as outlined in section 2.2 above; details of the age-depth model (reference timescale etc.) are stored at record level.

- series list: this table is just a list of the proxy data series associated with the record; there will usually be at least one data series, but there might be several, each with different sampling intervals; each series can have data for multiple different proxies and associated information; where there are climatic reconstructions made from proxies the method used for these is shown at series level; each proxy data series can have multiple references.

- proxies: this table contains the actual proxy data against depth for the records and any reconstructed climatic parameters. The database allows the user to mark data as null so that breaks in data series can be identified.

- relationships: this table holds the global list of time-scale relationships (time-transfer functions) available to link a pair of records; together with the age-depth models, these provide the linkages in the integration network; each relationship has one reference, which should provide an explanation of the relationship and the underlying data (or references to that data).

- time-transfer: this is the time-transfer data for a pair of records as described in section 2.3 above.

- events: this table provides a summary of the main INTIMATE event stratigraphy (currently N. Atlantic region only); each event can have multiple references associated with it and its timing must be specified in terms of a specific timescale; within the integration this event stratigraphy is treated like a special record.

- eruptions: as for the events table, this contains a list of key eruptions visible in a number of sites; each eruption has a single date estimate associated with it against one of the reference timescales and a reference from which this date is taken; this table is shared with the RESET 4 database (Bronk Ramsey et al., 2014) where there is much more information on the eruptions, composition of tephra and associated references; the eruptions in this database are primarily those relevant to the European and North African regions which were the focus of the RESET project.

- references: this table holds all the bibliographic information associated with the data stored in the data; the principle here is that everything in the database should be traceable to published sources and that when data are extracted from the database a comprehensive bibliography is provided to go with that data.

$\overline{4}$ Response of Humans to Abrupt Environmental Transitions; see http://c14. arch.ox.ac.uk/reset/ 


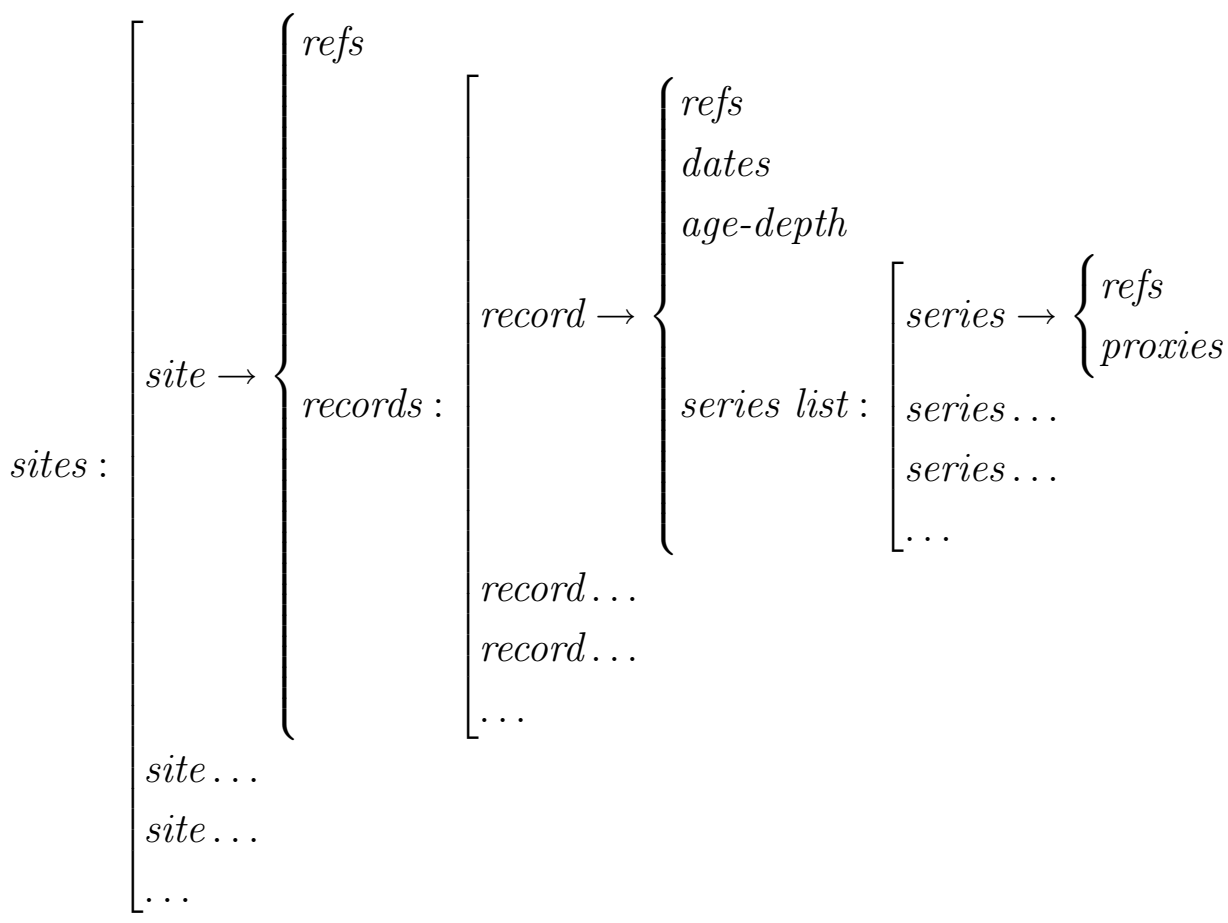

Fig. 3. The main structure of data in the database relating to temporal records. In this figure [ brackets denote arrays and $\{$ records within the database; the term refs refers to a series of links to the references table (effectively citations).

\section{Database implementation}

The database described here, uses the open-source MySQL package and a web interface based on php. The database is available online at https:// c14.arch.ox.ac.uk/intimate/db.php. The database is currently read-only for those not involved with the database development and the INTIMATE project.

\subsection{Navigation of the database}

The interface of the database is designed to be intuitive to use. There are essentially three different methods that can be used to navigate around the database: firstly, from the front page there are a number of links to frequently used pages (see Fig. 5); secondly, the menu bar at the top of the database page allows users to go to key pages wherever they are in the database; finally, almost all of the data presented in the database are hot-linked so it is easy to browse the information available.

The menu of the database has four main components: 


$$
\begin{aligned}
& \text { relationships }:\left[\begin{array}{l}
\text { relationship } \rightarrow\left\{\begin{array}{l}
\text { ref } \\
\text { time-transfer }
\end{array}\right. \\
\text { relationship } \ldots \\
\text { relationship } \ldots \\
\ldots
\end{array}\right. \\
& \text { events : }\left[\begin{array}{l}
\text { event } \rightarrow\{\text { refs } \\
\text { event } \\
\ldots
\end{array}\right. \\
& \text { eruptions : }\left[\begin{array}{l}
\text { eruption } \rightarrow\{r e f \\
\text { eruption } \\
\ldots
\end{array}\right. \\
& \text { references }:\left[\begin{array}{l}
\text { reference } \rightarrow\{\text { ref } \\
\text { reference } \\
\ldots
\end{array}\right.
\end{aligned}
$$

Fig. 4. The structure of the supporting tables in the database. See caption of Fig. 3 for further explanation and also note that the term ref refers to a single link to the references table whereas refs refers to multiple such links

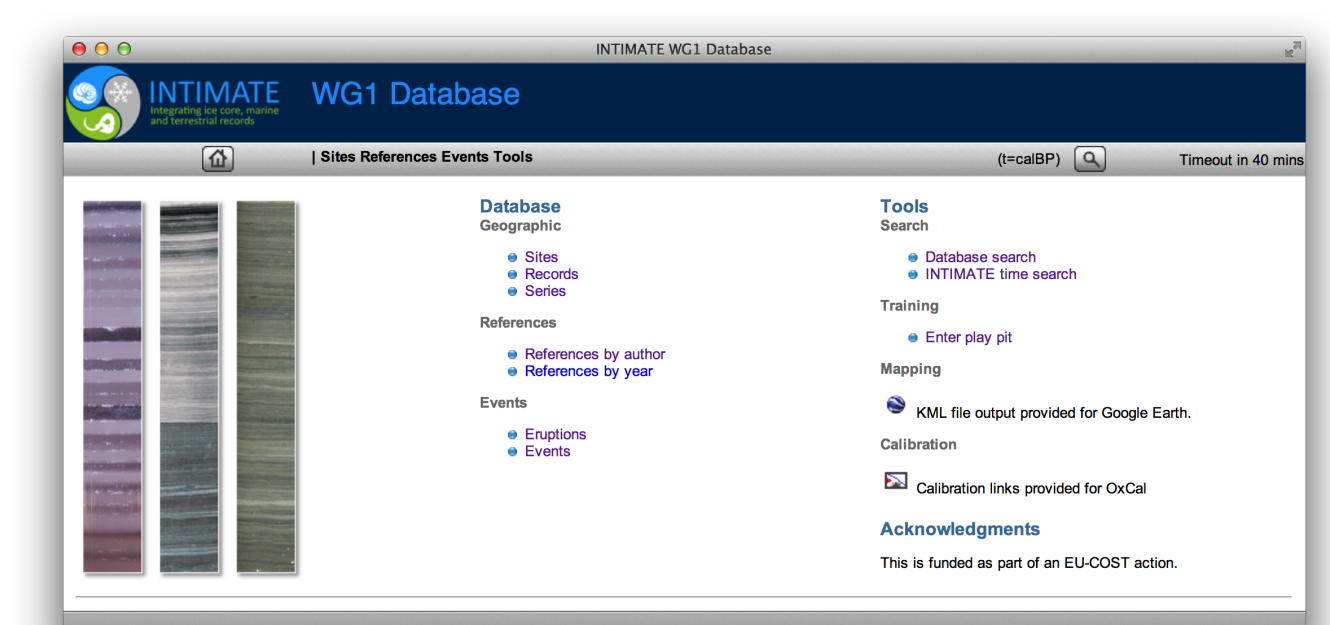

Fig. 5. Home screen of the database developed for the chronological working group (WG1) of North Atlantic INTIMATE. 
- File allows users to print, save (if they have permission) and export data from the database; they can also log out of the database or change their password from here.

- Edit allows users to select details of their search, and if they have permission to set the database to edit mode.

- View gives access to different views of the displayed data

- Sites gives access to a list of sites, records and data series

- References allows users to view references by first author or year

- Events lists the INTIMATE event stratigraphy and volcanic eruptions (currently N. Atlantic region only)

- Tools gives access to a number of tools, including the most important INTIMATE 'Time search'.

The main pages of the database reflect the structure of the database described in section 3 above. In general, the information is presented in a series of data panes. For example, looking at the page for a specific record (see Fig. 6), provides a summary of the data for that record and a series of tabs with information on series list, age-depth model, the dates that have been used for the age-depth model, tephras found in the record, any relationships between this record and others, and finally a list of references for this record. At the bottom of the page it shows a full list of references for the site, record and associated data series.

Any items shown in blue on the database page are hot-linked and can be used to get more detail on that item. In addition, the $\triangleleft$ button allows users to go to the parent of any page (so for example from a record page to the associated site page).

All of the chronological information stored on the database is internally stored as astronomical years. However, this may well not be the form in which the user wishes to use it. For this reason the database can be set to display chronological information in one of three formats: Astronomical years (CE), b2k (specifically intended for use with GICC05) and calBP (which is defined to be before AD 1950). Wherever it is relevant it is possible to change which format is used by using the View menu. The database shows in the top right which form of date is being employed (for example ' $t=$ calBP').

The pages of the database will normally just present data in tables. These data can be exported using the File menu; there is a choice of formats of which csv is probably the most useful; all of the different data tables shown will be exported.

In many cases users may wish to show the data graphically. This can be done using the View menu (see sections 4.3 and 4.4 below). 


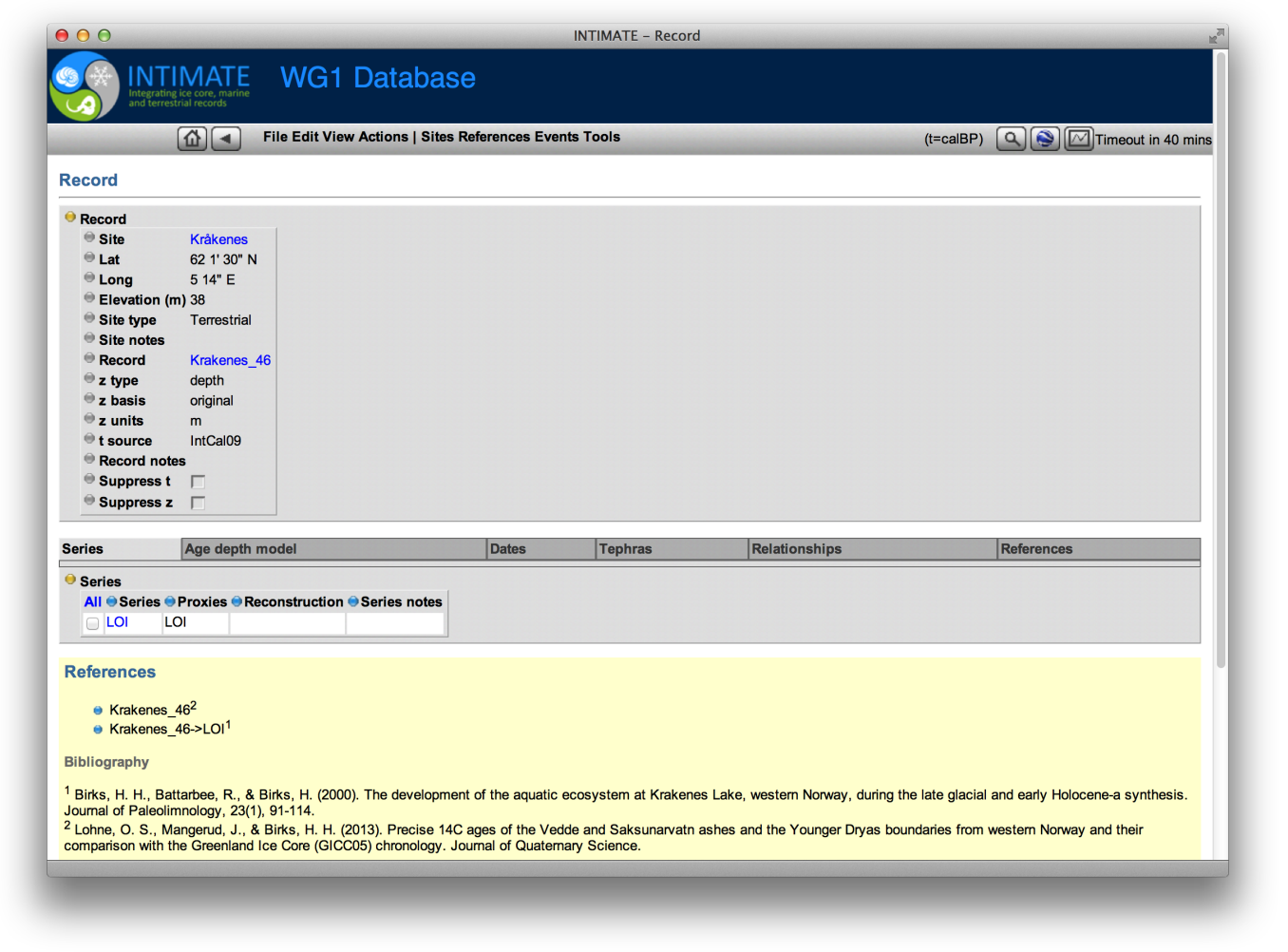

Fig. 6. Example record page from the INTIMATE database.

\subsection{Integration of data from a specific time-period}

The key motivation behind this database is integration of records, and so this is the most important aspect of the package. To use this facility users can either use the 'INTIMATE time search' link on the front page of the database, or use the menu system [Tools $>$ Time search]. This will pull up a list of the data series in the database and the provide the option to select a time period. Here the time slice of interest should be entered in the 'From' (oldest) and 'To' (youngest) boxes in the active date format. It is also possible to select which data series to draw data from, using the select boxes down the left. If none are selected the assumption is that data from all data series are required. After this selection the user should press the [Search] button. This will pull all of the relevant information from the database, but at this stage no integration of the data has taken place.

Next users can either press the [Plot] button, or use the [View $>$ Plot data] menu item. This will tell the browser to integrate the timescales using the mathematical methods outlined in section 2 above. There may be a slight delay while the calculations take place before the plot window is opened. 


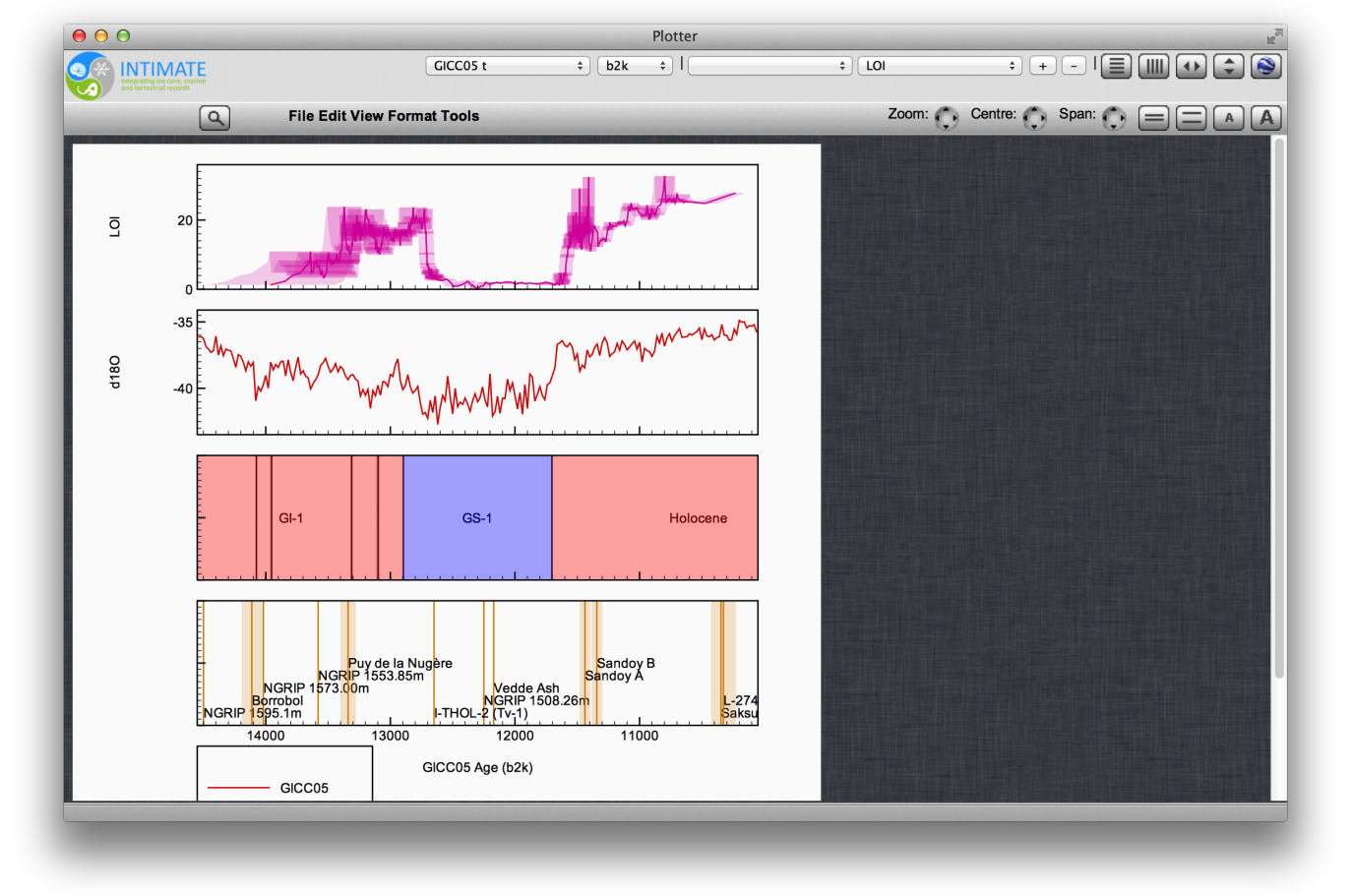

Fig. 7. Plotting interface for the database. See Fig. 8 for further details.

\subsection{Plotting data}

All plots are generated dynamically and use plotting routines which have been developed for OxCal (Bronk Ramsey and Lee, 2013) but with additional tools specifically for use with this database. There are a number of different database pages from which data plotting is possible.

The plotting of integrated data is the most important aspect of the database (see details of the integration process in the previous section). The user is presented with a plot of proxy against a default timescale (for example GICC05). There are also two additional plots shown, one displaying the INTIMATE event stratigraphy, and the other presenting the tephras that are recorded for this time interval (see Fig. 7; these plots should only be used if they are appropriate for the region of study. Uncertainties $(1 \sigma)$ in time, depth or proxy values are displayed as ribbons along the data series.

The top panel of the plotting tool has items specific to this database:

- There is a drop-down selection list at the top of the plot which allows the user to select a different timescale or depth scale to use to plot against, and another one which allows different units to be selected for date or depth. On doing this, the user will see that the uncertainties in the time or depth associated with the different proxies change and that there might be small 
changes in absolute dates on the different time-scales depending on how they are related. This is the main way of displaying the output of the integration of timescales.

- Users may wish to hide some of the plot panels which can be done by selecting the proxy name and pressing the [-] button; the plot can be restored by pressing the $[+]$ button. As a default, all proxy parameters are plotted together and so, for example, if several different records each have $\delta^{18} \mathrm{O}$ data-series, these will all be shown together; in some instances, this may not be convenient and so specific plot panels can be created for proxies from individual records by selecting the record and proxy and then pressing the $[+]$ button (and removed by pressing the [-] button).

- Finally, there is a series of buttons which allow users to change the orientation of the plots, and a globe button which shows the records on a map (see next section).

Plots can also be generated from a number of other pages in the database. In particular plotting data for a particular record will just plot the proxies for that record against the directly related time and depth scales (see Fig. 8). The same can be performed for a specific series too.

The remainder of the plotting window is common to all plots from this database, the RESET database, or some plots from the OxCal program. Manipulation of the plots can be done using the menu system:

- File: Most importantly this allows the user to save the plot (normally downloaded) as a pdf, svg or png format graphics file. It is also possible to print the plot (which, depending on the operating system, may enable it to be saved as a pdf file). The other important feature is the ability to export the data; this will export all of the data associated with the plot to a single csv file which can then be manipulated with a spreadsheet. This is another way to use the output of the timescale integration performed by the database. It is also possible to set some options such as relative font size and spacing here, or to reset these to defaults.

- Edit: This has options related to the data shown on the plot. Datasets can be selected for display and the line, marker types and colors used can all be set here. The data can also be viewed in detail and exported one dataset at a time (to csv format). In principle, data can also be imported through the edit option, but note that this will only display data on the plots and will not perform the integration of timescales which is part of the database package.

- View: This is where details of what is plotted can be altered, including axes and labels.

- Format: Enables control over plot dimensions, overall colour scheme and type of map (see next section). 


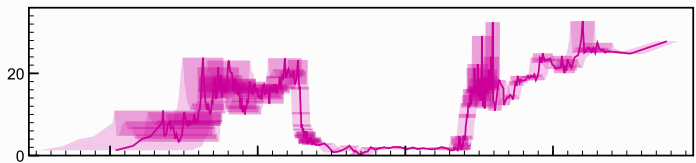

$\stackrel{\circ}{\frac{\infty}{5}}$
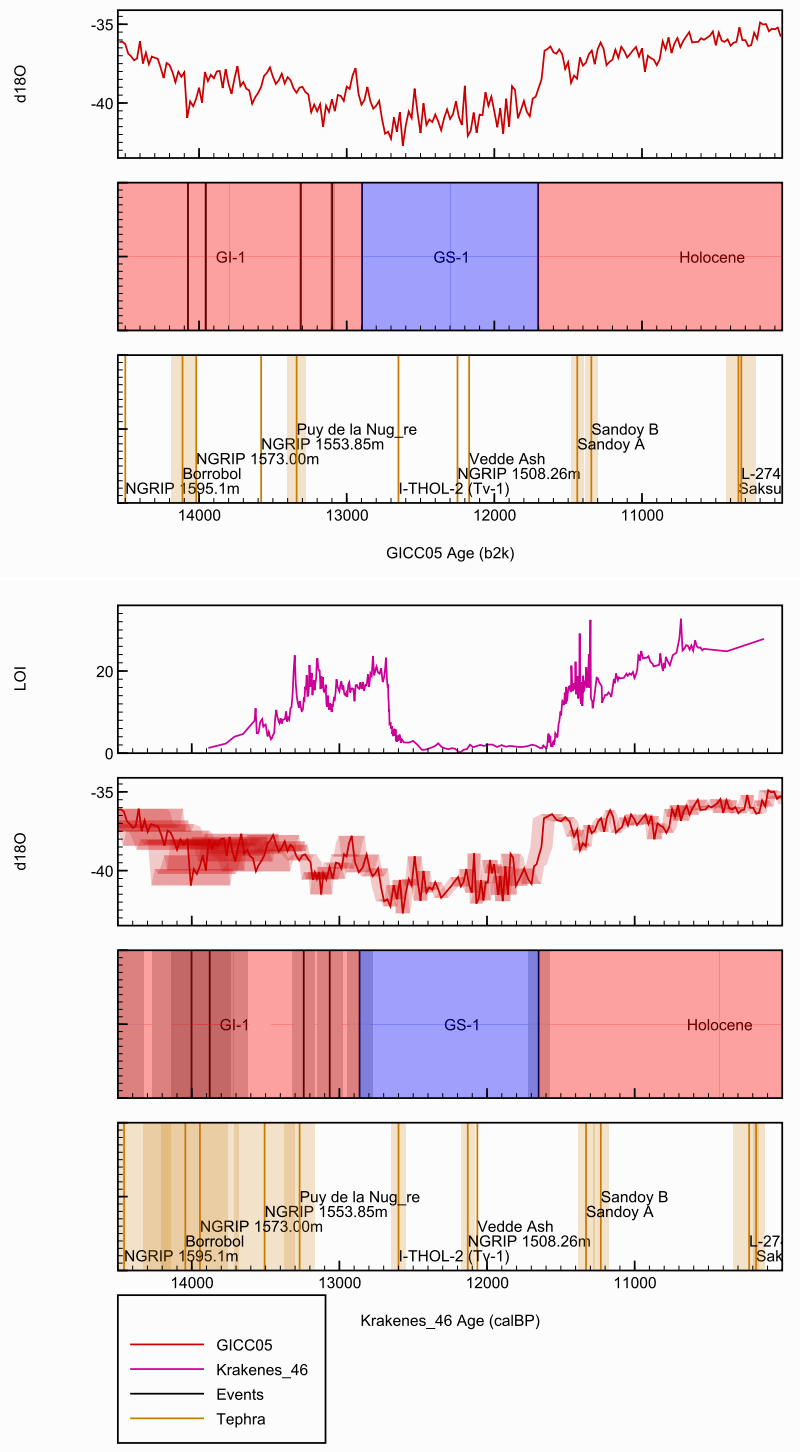

Fig. 8. This shows typical output from the database, showing the loss on ignition (LOI) data from Kråkenes (Lohne et al., 2013) alongside the $\delta^{18} \mathrm{O}$ record from NGRIP (NGRIP members, 2004 Rasmussen et al., 2006). The upper plots are shown on the GICC05 timescale (Rasmussen et al., 2006), while the lower plots are on Kråkenes's own timescale (based on IntCal09; Reimer et al., 2009). The different temporal uncertainties, when looked at from these different perspectives, are the key output from the integration. Note that the event stratigraphy uncertainties are also different between the two plots. Similar plots could also be obtained: for example, against the IntCal09 timescale or against depth in the Kråkenes record. Note that, for example, the Vedde Ash (just before 12000 cal BP) has high chronological precision in both timescales as this tephra is found in both records. 
In addition to being able to control axes through this menu system, the data can also be manipulated by clicking and dragging. If the user clicks on a plot they can reposition the data axes dynamically, allowing them to explore a dataset in more detail. Using the [Shift] key while dragging will allow the scale to be expanded or contracted. Using the [Alt] key while dragging changes the size of the entire plot.

\subsection{Mapping data}

In order to help with the exploration of data in its geographic context, the database also has rudimentary mapping functions. The mapping is provided as part of the plotting routines (see previous section), with an underlay map. The maps themselves can either be a simple world map which is provided in svg format, or can use any of the main Google ${ }^{\mathrm{TM}}$ map formats which are directly linked from the Google website. The Google ${ }^{\mathrm{TM}}$ maps are fine for screen display, and can be printed, but cannot be saved as plots for further editing.

Mapping can be used for a number of different purposes. It can be used just to show the location of sites or records within the database. In this form the points on the map are also hot-linked back to the database; clicking on the marker for a particular site in the map will open a new database page showing all of the data from that particular location.

Given that the focus of the database is on timescales, and associated proxy data, the main purpose of mapping is to show proxy data for particular timeslices. To view data which come from integration of timescales (see previous two sections), or from a particular record, users first plot the data (previous section) and then press the globe button on the top right. This allows them to choose the time range that they are interested in, and the time increments for any multiple plots. Optionally, they can also adjust the marker size. They are then presented with a map which shows the sites and colour codes them according to the value of a particular proxy at a particular time (the proxy can be chosen from the top panel, as can the timescale used). There is a slider at the bottom of the plot which can be used to move through the timescale, and buttons which allow the user to animate this process, showing how the proxy varies over time at different sites (see Fig. 9). Within the plotting program the menu item [View $>$ Multiplot] can be used to show the map at a range of time-slices. The slider at the bottom of the page then needs to be positioned to choose the starting time for the set of maps. 


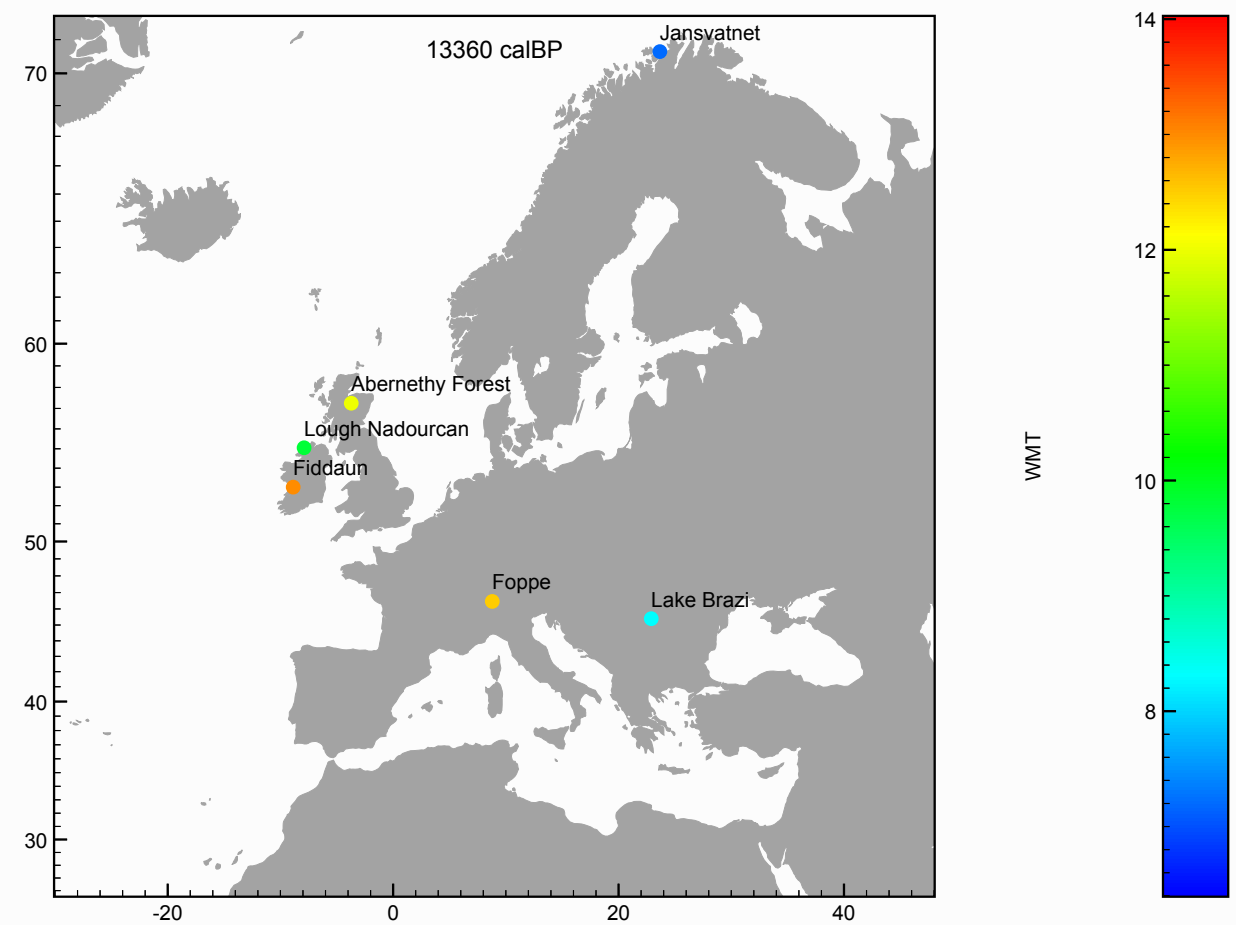

Fig. 9. An example map generated directly from the database. The plot shows the reconstruction of Warmest Month Temperature (WMT) in ${ }^{\circ} \mathrm{C}$ for a number of sites (Watson et al., 2010, Birks et al., 2012, Brooks et al., 2012, Samartin et al., 2012, Tóth et al., 2012, van Asch et al., 2012) in Europe at 13,360 cal BP (IntCal09 timescale; Reimer et al., 2009). Note that, because a colour scale is used, the uncertainties in reconstructed temperature and timescale are not currently reflected in these maps.

\subsection{GICC05 to IntCal linkage}

In practice the tools described here are made particularly useful by the ability to quantify the linkage between the GICC05 and IntCal timescales.

The transfer function between IntCal and Greenland ice core (GICC05) time scale is based on the variations in the incoming galactic cosmic ray flux that produce globally synchronous variations in the cosmogenic radionuclide production rates. These can be seen as variations in the atmospheric ${ }^{14} \mathrm{C}$ concentration as recorded in e.g. tree rings or as variations in ${ }^{10} \mathrm{Be}$ concentrations in ice cores. The variations can be used for very accurate ${ }^{14} \mathrm{C}$ dating $($ Pearson, 1986) but also for comparing and transferring the time scales of different natural archives. However, this exercise requires that the known geochemical differences between the different radionuclides are accounted for before a time scale comparison can be attempted. 
In the case of ice core ${ }^{10} \mathrm{Be}$ records it is important to isolate the production signal and minimize the climate influence. In a first approximation this is achieved by calculating the ${ }^{10}$ Be fluxes (e.g. Yiou et al., 1997). Furthermore, the average atmospheric residence time of ${ }^{10} \mathrm{Be}$ of about one year needs to be considered (Raisbeck et al., 1981). In the case of ${ }^{14} \mathrm{C}$ the known influences of the carbon cycle on the atmospheric ${ }^{14} \mathrm{C}$ concentration have to be taken into account (e.g. Siegenthaler et al., 1980). Here this is achieved by using a boxdiffusion carbon cycle model to reconstruct the ${ }^{14} \mathrm{C}$ production rate (Muscheler et al. 2005; Siegenthaler, 1983; Stuiver and Quay, 1980). However, the option in this model for a direct exchange of $\mathrm{CO} 2$ from the atmosphere to the deep ocean was not used. The results regarding modelled ${ }^{14} \mathrm{C}$ variations are very similar to results from more recent 3D carbon cycle models (Muscheler et al. 2007). The resulting production record is corrected for the effects of a delayed and dampened reaction of the atmospheric ${ }^{14} \mathrm{C}$ concentration to production rate changes.

The time scale transfer functions used here are based on the comparison of the spliced GRIP and GISP2 ${ }^{10}$ Be records (Finkel and Nishiizumi, 1997; Muscheler et al., 2004; Vonmoos et al., 2006; Yiou et al., 1997) and the Intcal09 and IntCal13 calibration records (Reimer et al., 2009, 2013). The time scales are compared via the identification of the best agreement between the ice core ${ }^{10} \mathrm{Be}$ and tree-ring based ${ }^{14} \mathrm{C}$ production rate variations. Error estimates are inferred from Monte-Carlo simulations where the records are varied within their uncertainties before the best fit of the time scales is assessed (for details see Muscheler et al., submitted). The maximum counting error of the ice core time scale is taken into account in the process but not as a hard limit since errors might come from either of the time scales involved in any transfer function. Continuous tree-ring based atmospheric ${ }^{14} \mathrm{C}$ estimates are restricted to about the last 14000 years. At the moment only these records allow reliable estimates and unequivocal matching of the short-term atmospheric ${ }^{14} \mathrm{C}$ variations. Therefore, the direct link between ice core and radiocarbon time scale is presently limited to this period, beyond which counting errors must be used to estimate uncertainty.

\subsection{Technical details}

The database has been designed to minimise server overheads so that performance of the database can be maintained with many users. For this reason the php code used for extraction of data from the database is fairly simple - and its function is primarily to allow secure access to the data and to perform the SQL searches on the database. The data from the database are then sent to the user as javascript arrays and objects. All of the presentation and numerical analysis of the data takes place on the client's machine within the javascript 
engine of the user's browser. This approach has several advantages: data only have to be retrieved once and all further analysis or different presentation does not require extra searches to be performed on the database, minimising the effect of low connection speeds; furthermore the server itself does not have to prepare data for presentation or do any numerical analysis, which improves performance of the system with multiple users. However there are also some disadvantages to this approach: the quantity of data being analysed can be quite high and client computers without much memory, or with low performance web-browsers may find that the system is slow to use, or cannot cope with searches that attempt to integrate very large quantities of data.

If users want to see how this works in practice, they should try the time search as explained in section 4.2 above and look at the page source. Here they will see the raw data extracted from the database as a javascript data object.

The numerical analysis code is all written in javascript and is therefore openly available. The main integration routines are all given in one file https://c14. arch.ox.ac.uk/intimate/integrator.js

All of the graphics generated by the database are also generated dynamically within the web-browser of the user. Again this has the advantage that these processor intensive tasks do not slow down the server. The graphics use the Scalable Vector Graphics (SVG) standard, compatible with most of the latest generation web-browsers. The plots generated can be saved in this format (editable with the open source Inkscape package or various commercial alternatives such as Adobe ${ }^{\mathrm{TM}}$ Illustrator), or can be converted to pdf or png format using Apache ${ }^{\mathrm{TM}}$ Batik toolkit installed on the server.

\section{$5 \quad$ Further developments}

The database as published here is a first attempt to bring together all of the timescale information from the INTIMATE project and use it to present associated proxy and inferred climatic reconstructions. Clearly, these ideas can be developed further and the authors expect future advances to depend on feedback from users allied to improvements in the generation of proxy datasets. However, there are already a number of areas that are being actively pursued to enhance the database:

- addition of datasets Clearly the data added at the INTIMATE data integration exercise in Blair Atholl was limited by what was available at the time, in the right form, and also by the age and geographic range of the North Atlantic INTIMATE group (see section 1). In principle, the approaches taken here could cover other regions and time-scales. To some extent this would 
simply be a matter of adding further data. However, especially if the data are to be used in different ways it may also be necessary to further develop the integration methodology and search criteria.

- search criteria At present the search criteria are limited to time-range. However, as the database expands it will clearly be necessary to add other filters and search tools that can make use of the data stored within the database. Feedback from users of the database on what types of search would be useful is encouraged by the authors.

- private data At present, all data within the database are presented to all users on the understanding that the data have all been through the peerreview process and have been published. However, it is clear that it would be beneficial for users to input their own data, but without making the data available to the community. This should help i) in the preparation of data for publication, ii) for students engaged in research as part of their studies, iii) help the workflow for getting new data onto the database.

- linkage with OxCal This database has deliberately been developed using much of the same core code as OxCal, sharing the plotting package OxPlot which is used for the mapping and graphics. The intention is to allow future versions of OxCal to link to the database directly, allowing data from the relevant time period to be plotted along-side radiocarbon calibrations and age-models produced by OxCal. In this way, the INTIMATE database can become a useful resource for people looking at environmental and archaeological information across this time period (the last $60 \mathrm{ka}$ ). In addition it would help the generation of age-models for users' own sites if it were possible to use the dates records from the database to generate age-depth models that could be run using OxCal automatically. The ease of record comparison does of course also pose some additional risks: this might tempt the user to choose age-models that agree with their understanding of the underlying processes; ideally the choice of age-modelling approach should be independently selected before comparison to other key records.

- time-transfer function generation At present, there is no automated way to generate the kinds of time-transfer functions needed here. In principle, this information could be extracted when two or more age-depth models are run together and so a future development envisaged for OxCal is to provide a simple means to extract time-transfer data in the format needed for this database.

- fluxes Some data make most sense understood in terms of flux rather than actual concentration. The ability to deal with this while changing between timescales would be a natural extension of the methodology presented here.

- data presentation There are a number of ways in which the data presentation might be further developed. Probably one of the most important would be some form of interpolation (either via Kriging or inverse distance weighted interpolation) between points for the mapping of reconstructed variables for specific time-slices; this would allow more direct comparison with model outputs. 


\section{Conclusions}

The approach taken here to integration of timescales makes use of what is a fairly simple mathematical approach, involving linear interpolation and assumptions of Normality in uncertainties. In this sense, what the tools set out here do, is something which would be possible for any numerically able researcher to undertake within packages such as $R$ (R Core Team, 2014) or MatLab $^{\mathrm{TM}}$, given sufficient time. Indeed, with particular records in mind it might be possible to make even better use of all the available information. The value of the methodology set out here is only realised in combination with the database which provides the relevant data in a form already suitable for integration. By using a simple web-based framework that does not require installation of any specialised software, this allows researchers to compare what is happening in different records very quickly and thus makes it possible to explore ideas and hypotheses interactively.

The database, as it is at time of publication, is necessarily a 'work in progress'. The database can be strengthened by the addition of more data from different records and the collection of these data is the focus of others involved in the INTIMATE initiative. In addition, because the overall framework outlined here is new, there will undoubtedly be ways in which it can be improved both in terms of the underlying methodology and the user-interface. However, it is hoped that the database, as it is presented, will provide a useful tool for those doing research in the late Quaternary.

\section{Acknowledgements}

The developments described here were made possible through collaboration at meetings supported by the EU-funded COST Action INTIMATE (ES0907). The database builds on the infrastructure for the RESET project funded by the UK Natural Environment Research Council (NERC): grant number: NE/E015670/1. The code for the database itself shares modules with the database of the Oxford Radiocarbon Accelerator Unit (ORAU), also supported by NERC as part of the NERC national radiocarbon facility. The database is hosted at ORAU on servers administered by the School of Archaeology, University of Oxford. 


\section{References}

Andersen, K. K., Svensson, A., Johnsen, S. J., Rasmussen, S. O., Bigler, M., Röthlisberger, R., Ruth, U., Siggaard-Andersen, M. L., Peder Steffensen, J., Dahl-Jensen, D., et al., 2006. The Greenland ice core chronology 2005, 15-42ka. Part 1: Constructing the time scale. Quaternary Science Reviews 25 (23), 3246-3257.

Birks, H. H., Jones, V. J., Brooks, S. J., Birks, J. H. B., Telford, R. J., Juggins, S., Peglar, S. M., 2012. From cold to cool in northernmost Norway: Lateglacial and early Holocene multi-proxy environmental and climate reconstructions from Jansvatnet, Hammerfest. Quaternary Science Reviews 33 (0), 100-120.

Blaauw, M., Christen, J. A., 2005. Radiocarbon peat chronologies and environmental change. Journal of the Royal Statistical Society Series C-Applied Statistics 54, 805-816.

Blockley, S. P. E., Lane, C. S., Hardiman, M., Rasmussen, S. O., Seierstad, I. K., Steffensen, J. P., Svensson, A., Lotter, A. F., Turney, C. S. M., Bronk Ramsey, C., project members, I., 2012. Synchronisation of palaeoenvironmental records over the last 60,000 years, and an extended INTIMATE(1) event stratigraphy to 48,000 b2k. Quaternary Science Reviews $36,2-10$.

Bronk Ramsey, C., 2008. Deposition models for chronological records. Quaternary Science Reviews 27 (1-2), 42-60.

Bronk Ramsey, C., Housley, R. A., Lane, C., Smith, V. C., Pollard, A. M., 2014. The RESET database and associated analytical tools. Quaternary Science Reviews submitted.

Bronk Ramsey, C., Lee, S., 2013. Recent and Planned Developments of the Program OxCal. Radiocarbon 55 (2-3), 720-730.

Brooks, S. J., Matthews, I. P., Birks, H. H., Birks, H. B., 2012. High resolution Lateglacial and early-Holocene summer air temperature records from Scotland inferred from chironomid assemblages. Quaternary Science Reviews $41(0), 67-82$.

Finkel, R., Nishiizumi, K., 1997. Beryllium 10 concentrations in the Greenland Ice Sheet Project 2 ice core from 3-40 ka. Journal of Geophysical Research: Oceans (1978-2012) 102 (C12), 26699-26706.

Heaton, T., Bard, E., Hughen, K., 2013. Elastic Tie-Pointing - Transferring Chronologies between Records Via a Gaussian Process. Radiocarbon 55 (4), 1975-1997.

Lemieux-Dudon, B., Blayo, E., Petit, J.-R., Waelbroeck, C., Svensson, A., Ritz, C., Barnola, J.-M., Narcisi, B. M., Parrenin, F., 2010. Consistent dating for Antarctic and Greenland ice cores. Quaternary Science Reviews 29 (1-2), 8-20.

Lohne, O. y. S., Mangerud, J., Birks, H. H., 2013. Precise 14C ages of the Vedde and Saksunarvatn ashes and the Younger Dryas boundaries from western Norway and their comparison with the Greenland Ice Core (GICC05) 
chronology. Journal of Quaternary Science 28 (5), 490-500.

Lowe, J. J., Rasmussen, S. O., Björck, S., Hoek, W. Z., Steffensen, J. P., Walker, M. J. C., Yu, Z. C., 2008. Synchronisation of palaeoenvironmental events in the North Atlantic region during the Last Termination: a revised protocol recommended by the INTIMATE group. Quaternary Science Reviews 27 (1-2), 6-17.

Muscheler, R., Adolphi, F., Beer, J., Knudsen, M., Svensson, A., submitted. Assessing the offsets between the IntCal09/13 and the Greenland ice core time scale for the last 14000 years via the common cosmogenic radionuclide variations. Quaternary Science Reviews submitted.

Muscheler, R., Beer, J., Kubik, P. W., Synal, H.-A., 2005. Geomagnetic field intensity during the last 60,000 years based on $10 \mathrm{Be}$ and $36 \mathrm{Cl}$ from the Summit ice cores and 14C. Quaternary Science Reviews 24 (16), 1849-1860.

Muscheler, R., Beer, J., Wagner, G., Laj, C., Kissel, C., Raisbeck, G. M., Yiou, F., Kubik, P. W., 2004. Changes in the carbon cycle during the last deglaciation as indicated by the comparison of $10 \mathrm{Be}$ and $14 \mathrm{C}$ records. Earth and Planetary Science Letters 219 (3-4), 325-340.

Muscheler, R., Joos, F., Beer, J., Müller, S. A., Vonmoos, M., Snowball, I., 2007. Solar activity during the last $1000 \mathrm{yr}$ inferred from radionuclide records. Quaternary Science Reviews 26 (1), 82-97.

NGRIP members, 2004. High-resolution record of Northern Hemisphere climate extending into the last interglacial period. Nature 431 (7005), 147-151.

Pearson, G. W., 1986. Precise Calendrical Dating of Known Growth-Period Samples using a 'Curve-Fitting' Technique. Radiocarbon 28, 292-299.

R Core Team, 2014. A Language and Environment for Statistical Computing. Vienna: R Foundation for Sta- tistical Computing.

URL http://www.R-project.org

Raisbeck, G., Yiou, F., Fruneau, M., Loiseaux, J., Lieuvin, M., Ravel, J., 1981. Cosmogenic $10 \mathrm{Be} / 7 \mathrm{Be}$ as a probe of atmospheric transport processes. Geophysical Research Letters 8 (9), 1015-1018.

Rasmussen, S. O., Andersen, K. K., Svensson, A. M., Steffensen, J. P., Vinther, B. M., Clausen, H. B., Siggaard-Andersen, M. L., Johnsen, S. J., Larsen, L. B., Dahl-Jensen, D., Bigler, M., Röthlisberger, R., Fischer, H., GotoAzuma, K., Hansson, M. E., Ruth, U., 2006. A new Greenland ice core chronology for the last glacial termination. Journal of Geophysical Research 111.

Rasmussen, S. O., Seierstad, I. K., Andersen, K. K., Bigler, M., Dahl-Jensen, D., Johnsen, S. J., 2008. Synchronization of the NGRIP, GRIP, and GISP2 ice cores across MIS 2 and palaeoclimatic implications. Quaternary Science Reviews 27 (1-2), 18-28.

Reimer, P. J., Baillie, M. G. L., Bard, E., Bayliss, A., Beck, J. W., Blackwell, P. G., Bronk Ramsey, C., Buck, C. E., Burr, G. S., Edwards, R. L., Friedrich, M., Grootes, P. M., Guilderson, T. P., Hajdas, I., Heaton, T. J., Hogg, A. G., Hughen, K. A., Kaiser, K. F., Kromer, B., McCormac, F. G., Manning, S. W., Reimer, R. W., Richards, D. A., Southon, J. R., Talamo, 
S., Turney, C. S. M., van der Plicht, J., Weyhenmeyer, C. E., 2009. IntCal09 and Marine09 radiocarbon age calibration curves, 0-50,000 years cal BP. Radiocarbon 51 (4), 1111-1150.

Reimer, P. J., Bard, E., Bayliss, A., Beck, J. W., Blackwell, P. G., Bronk Ramsey, C., Grootes, P. M., Guilderson, T. P., Haflidason, H., Hajdas, I., Hatté, C., Heaton, T. J., Hoffmann, D. L., Hogg, A. G., Hughen, K. A., Kaiser, K. F., Kromer, B., Manning, S. W., Niu, M., Reimer, R. W., Richards, D. A., Scott, E. M., Southon, J. R., Staff, R. A., Turney, C. S. M., van der Plicht, J., 2013. IntCal13 and Marine13 Radiocarbon Age Calibration Curves 050,000 Years cal BP. Radiocarbon 55 (4), 1869-1887.

Samartin, S., Heiri, O., Vescovi, E., Brooks, S. J., Tinner, W., 2012. Lateglacial and early Holocene summer temperatures in the southern Swiss Alps reconstructed using fossil chironomids. Journal of Quaternary Science 27 (3), 279-289.

Schlolaut, G., Marshall, M. H., Brauer, A., Nakagawa, T., Lamb, H. F., Staff, R. A., Ramsey, C. B., Bryant, C. L., Brock, F., Kossler, A., Tarasov, P. E., Yokoyama, Y., Tada, R., Haraguchi, T., 2012. An automated method for varve interpolation and its application to the Late Glacial chronology from Lake Suigetsu, Japan. Quaternary Geochronology 13, 52-69.

Scholz, D., Hoffmann, D. L., 2011. StalAge - An algorithm designed for construction of speleothem age models. Quaternary Geochronology 6 (3-4), 369-382.

Siegenthaler, U., 1983. Uptake of excess CO2 by an outcrop-diffusion model of the ocean. Journal of Geophysical Research: Oceans (1978-2012) 88 (C6), 3599-3608.

Siegenthaler, U., Heimann, M., Oeschger, H., 1980. 14C variations caused by changes in the global carbon cycle. Radiocarbon 22 (2), 177-191.

Stuiver, M., Quay, P. D., 1980. Changes in atmospheric carbon-14 attributed to a variable sun. Science 207 (4426), 11-19.

Svensson, A., Andersen, K. K., Bigler, M., Clausen, H. B., Dahl-Jensen, D., Davies, S., Johnsen, S. J., Muscheler, R., Parrenin, F., Rasmussen, S. O., et al., 2008. A 60000 year Greenland stratigraphic ice core chronology. Climate of the Past 4 (1), 47-57.

Svensson, A., Andersen, K. K., Bigler, M., Clausen, H. B., Dahl-Jensen, D., Davies, S. M., Johnsen, S. J., Muscheler, R., Rasmussen, S. O., Röthlisberger, R., Steffensen, J. P., Vinther, B. M., 2006. The Greenland Ice Core Chronology 2005, 15-42 ka. Part 2: comparison to other records. Quaternary Science Reviews 25 (23-24), 3258-3267.

Tóth, M., Magyari, E. K., Brooks, S. J., Braun, M., Buczkó, K., Bálint, M., Heiri, O., 2012. A chironomid-based reconstruction of late glacial summer temperatures in the southern Carpathians (Romania). Quaternary Research 77 (1), 122-131.

van Asch, N., Lutz, A. F., Duijkers, M. C. H., Heiri, O., Brooks, S. J., Hoek, W. Z., 2012. Rapid climate change during the Weichselian Lateglacial in Ireland: Chironomid-inferred summer temperatures from Fiddaun, Co. Galway. 
Palaeogeography, Palaeoclimatology, Palaeoecology 315-316 (0), 1-11.

Vonmoos, M., Beer, J., Muscheler, R., 2006. Large variations in Holocene solar activity: Constraints from 10Be in the Greenland Ice Core Project ice core. Journal of Geophysical Research: Space Physics (1978-2012) 111 (A10).

Watson, J. E., Brooks, S. J., Whitehouse, N. J., Reimer, P. J., Birks, J. H. B., Turney, C., 2010. Chironomid-inferred late-glacial summer air temperatures from Lough Nadourcan, Co. Donegal, Ireland. Journal of Quaternary Science 25 (8), 1200-1210.

Yiou, F., Raisbeck, G., Baumgartner, S., Beer, J., Hammer, C., Johnsen, S., Jouzel, J., Kubik, P., Lestringuez, J., Stievenard, M., et al., 1997. Beryllium 10 in the Greenland ice core project ice core at summit, Greenland. Journal of Geophysical Research: Oceans (1978-2012) 102 (C12), 26783-26794. 